verschwinden lassen wird. Die Isolirung des riechenden Princips aus Blumen nach obiger Vorschrift im grössten Maassstabe ausgeführt, wird mit grossen Kosten verbunden sein. Im Kleinen führt sie nicht zu einem günstigen Ziele. Die Ueberführnng des riechenden Princips aus wohlriechenden Blumen wird daher wohl nur auf die bis jetzt bekannte Weise geschehen können.

$B$.

\title{
Baryt in Pflanzenaschen.
}

Scheele entdeckte bei seiner Untersuchung des Braun. steins den Baryt und fand letzteren auch in den Pflanzenasohen. "Arborum fruticumve cimeres diligentissime elot., ut quicquid infuerat tartari vitriolati, subtractum sit, acidum purum nitri aut muriae subeant: percolatamque solutionem aqua diluat. Cui si guttas aliquot acidi vitriolici indideris, post horae quadrontem praecipitatum subtile al. bumque habebis. Id hac ipsa terra accidoque vitriolico constat, nec quidquam ab illo praecipitato, de quae saepius egimus (nämlich vom schwefelsauren Baryt) discordat. (Caroli Guill. Scheele opuscula chemioa et physica. Vol. I. Lipsiae 1788. p. 258.)

G. E. Eckardt aus Berlin fand im Laboratorium des physiologischen Instituts zu Göttingen unter Leitung des Prof. Bödeker den Baryt in der Buchenholzasche. Diese, aus dicken Holzscheiten, aus dem Innern genommenen Splitter, aufs sorgfältigste bereitet, gaben mit Wasser vollständig ausgewaschen einon Rückstand, der in Salzsäßre gelöst, mit Gypswasser sich erheblich trübte. Eine Auflösung von schwefelsaurem Strontian gab in der sauren Lösung keine Trübung. Der erhaltene schwefelsaure Baryt wurde mit kohlensaurem Alkohol zerlest und in Chlorbaryum verwandelt.

H. Lutterkorth aus Tilsit fand kohlensauren Baryt im Sandstein aus der Gegend von Göttingen. (Bödeker, Ann. der Chem. und Pharm. Dec. 1856. p. 294-296.)

Versuche, in unserm chemisch-pharmaceutischen Laboratorium angestellt, haben ergeben, dass das FichtennadelExtract aus der Apotheke des Herrn Dufft in Rudolstadt ebenfalls deutlich nachweisbare Mengen von Baryt enthält. Dr. H. Ludwig.

\section{Veber die schädliche Binwirkung des Meerwassers auf Pflanzungen.}

Dass die Kinwirkung des Meerwassers den meisten Pflanzen schädlich sein dürfte, hat die Erfahrung bewie- 